\title{
The Caprine casein-alpha-S2 protein modulates the molecular mechanism of insulin signal transduction in type 2 diabetes rat
}

\author{
Fatchiyah Fatchiyah ${ }^{1,2} \square$, Rista Nikmatu Rohmah1,3, Lidwina Faraline Triprisila1,3, \\ Takeshi Ohta ${ }^{1,4}$ and Hazna Noor Meidinna1,5
}

1Research Center of Smart Molecule of Natural Genetics Resource, Brawijaya University, Malang, East Java, Indonesia; ${ }^{2}$ Department of Biology, Faculty of Mathematics and Natural Sciences, Brawijaya University, Malang, East Java, Indonesia; 'Biosains Institute, Brawijaya University, Malang, East Java, Indonesia; ${ }^{4}$ Graduate School of Agriculture, Kyoto University, Kyoto, Japan; ${ }^{5}$ DBT-AIST International Laboratory for Advanced Biomedicine (DAILAB), National Institute of Advanced Industrial Science \& Technology (AIST), and Tsukuba Life Science Innovation, Graduate School of Comprehensive Human Sciences, University of Tsukuba, Tsukuba, Ibaraki, Japan

The purpose of this study was to investigate the association of casein-alpha-S2 protein of Caprine milk and molecular mechanism of insulin signal transduction in type 2 diabetes mellitus (T2DM). We divided 24 experimental rats into two major groups, namely control and DM group. The Caprine milk CSN1S2 protein treatment of 0 , 375,750 , and $1500 \mathrm{mg} / \mathrm{kg} \mathrm{BW}$ was administered to the control and DM rats. We observed several physiological parameters of all rats. The levels of insulin and TNF- $a$ in the plasma were measured using ELISA. The expressions of proteins and mRNA levels of diabetes-related genes in the pancreas tissues were analyzed using Western Blotting and Real-Time PCR, respectively. Our study found that there was no improvement in the blood glucose and cholesterol level of DM rats treated with CSN1S2. Interestingly, the expression of genes associated with insulin signaling was improved by the CSN1S2 protein treatment in diabetic rats. The diabetic rats showed an elevated insulin level and GLUT4 protein expression after treatment. We also reported that the CSN1S2-treated diabetic rats had a gradually reduced expression of TNF- $a$ and VCAM1 in dose-dependent manner. Moreover, the $750 \mathrm{mg} / \mathrm{kg} B W$ of CSN1S2 treatment enhanced the mRNA expressions of INSR, GLUT4, IGF1, CAMKK, and CAMK4 in diabetic rats. The ability of Caprine milk CSN1S2 protein to regulate the molecular mechanisms in the diabetes-signaling pathway indicated its potential therapeutic effects on diabetes management.

Key words: casein-alpha-S2, diabetes, insulin, GLUT4, nutrition

Received: 27 April, 2020; revised: 05 June, 2020; accepted: 17 June, 2020; available on-line: 14 September, 2020

Đe-mail: fatchiya@ub.ac.id

Acknowledgements of Financial Support: We thank the Ministry of National Education and Ministry of Research and Technology/ National Agency for Research and Innovation of the Republic of Indonesia for Fund supporting the national research grant of PDUPT 2018-2020. Thanks a lot to Biosains Institute, Brawijaya University, for providing the laboratories and facilities.

Abbreviations: CAMK4, calcium/calmodulin dependent protein kinase IV; CAMKK, calcium/calmodulin dependent protein kinase kinase; ELISA, enzyme-linked immunosorbent assay; GLUT4, glucose transporter type 4; IGF1, insulin like growth factor 1; INSR, insulin receptor; PVDF, polyVinyliDene fluoride; T2DM, type 2 diabetes mellitus; TNF, tumor necrosis factor; STZ, Streptozotocin; VCAM, Vascular Cell Adhesion Molecule.

\section{INTRODUCTION}

Nutrition-gene interaction plays a role in modifying cellular signaling pathways at the molecular level. It can induce the molecular and physiological dysfunction of gene cascade increasing susceptibility to metabolic diseases, such as dyslipidemia and type 2 diabetes. Type 2 diabetes mellitus is a metabolic disorder caused by different factors, including hereditary qualities, epigenetics, and environmental variables such as improper nutrition, unbalanced diets, and lack of exercise. These risk factors influence the outflow of qualities engaged in insulin biosynthesis in $\beta$-cells and insulin secretion across peripheral tissues (Dauncey, 2012; Fatchiyah et al., 2017b; Kang et al., 2020). The lack of insulin and diet composition affects the downstream insulin signaling in type 2 diabetes. The diet has been associated with insulin resistance and hyperglycemia in type 2 diabetes. The nutrients may activate indirectly the insulin signaling stimulated by phosphorylation of insulin receptor substrate (IRS) proteins and then induce the glucose transport through the PI3-K downstream activation (Cepas et al., 2020; Kang et al., 2020). It is understood that some nutrient substances alter metabolic signaling in diabetic cells. Moreover, molecular mechanisms in tissues of the body can regulate underlying bioactive nutritional composition according to the individual differences in multiple target genes. There are very interesting aspects to explore on the communication of nutrition - gene regulation in type 2 diabetes.

The insulin signaling regulation is a mechanism highly considered to account for understanding diabetes and its management (Saif-Ali et al., 2011; Cieślak et al., 2015). Insulin control of target cells is transferred from the insulin receptor (INSR) at the cell surface to different cellular processes such as glucose uptake through an intracellular signaling network. Insulin-IR interaction is believed to transduce signals by phosphorylation on Tyr residues of insulin receptor substrate (IRS) proteins. The high concentrations of glucose promote the insulin gene transcription and enhance the biosynthesis of insulin at the post-translational level at the critical limits of the physiological maintenance (Brännmark et al., 2013; Lorenzo et al., 2008). Some mutations in the tyrosine kinase domain of IR inhibit the IRS1 signal transduction inside target cells. A report of our research in diabetes patients had shown the nucleotide mutation of the tyrosine kinase domain of the insulin receptor gene inhibited the activation of IRS1 signal transduction. We described a deletion resulting in a frameshift mutation at codon 1274 followed by premature termination after four additional amino acids (p.Gln1274HisfsX5). This mutation led to the shortened 3D-structure of the tyrosine domain of 
INSR with incomplete post-translational modifications (Fatchiyah et al., 2013). A mutation in one allele generating a stop codon at amino acid 897 in the extracellular domain of the $\beta$-subunit of INSR gene has caused a nonfunctional insulin receptor (Iovino et al., 2014). The tyrosine kinase domain of insulin receptor has a self-blockade depending on the projection of an activation loop tyrosine residue into the substrate-binding site and closure of the ATP-binding site by the activation loop that induces important metabolic and endocrine function (Nobile et al., 2012). The alterations of the activation status of the proximal insulin signaling enzymes and downstream targets have been studied in muscle and adipose tissue in cases of insulin resistance, obesity, and type 2 diabetes. These conditions caused abnormalities in the insulin signaling cascade in target tissues (Huang \& Czech, 2007; Fröjdö et al., 2009; Brännmark et al., 2013). The conditional depletion of glucose transporter type 4 (GLUT4) in either adipose tissue or skeletal muscle causes insulin resistance and a roughly equivalent incidence of diabetes in animals. These tissue-specific depletions of GLUT4 have profound metabolic effects on other tissues. In the hepatic cell, as an insulin target tissue, insulin resistance can be stimulated by inflammatory cytokine TNF- $\alpha$ (Huang \& Czech, 2007; Saif-Ali et al., 2011). It is possible that using nutrients and gene-nutrition interactions might alleviate the defect of insulin signal transduction pathway. One group of the potential nutrients are bioactive peptides of goat milk protein.

Goat milk-derived bioactive peptides promote better digestibility, buffering capacity, and alkalinity than ones from cow's milk and besides bring certain therapeutic values in medicine and human nutrition. The protein in goat milk has constituent amino acids that are efficiently absorbed and easily digested. Our study found that $36 \mathrm{kDa}$ of fresh milk and yogurt identified by MALDI TOF analysis was a single casein-alpha-S2 (CSN1S2) protein. The seven of eight of bioactive peptides residues of CSN1S2 protein have the specific biological function as anti-inflammatory, anti-bacterial, and anti-oxidant (Fatchiyah et al., 2015). The bioactive peptides of Caprine milk might have a function as immunomodulators causing nutrition-gene cascade communication to regulate cellular mechanism signaling in prevention for type 2 diabetes. Therefore, this study fo-

Table 1. Specific Primer Sequences for RT-qPCR

\begin{tabular}{|c|c|c|c|}
\hline Genes & Sequence & Function & References \\
\hline \multirow{2}{*}{ INS } & INS-F-5'-ATAGACCATCAGCAAGCAGG-3' & \multirow{2}{*}{$\mathrm{qPCR}$} & \multirow{2}{*}{ Yu et al., 2004} \\
\hline & INS-R-5'-CTCCAGTTGTGGCACTTGCG-3' & & \\
\hline \multirow{2}{*}{ INSR } & INSR-F-5'-GAAAAAATTGCGGCGGGAGG-3' & \multirow{2}{*}{$\mathrm{qPCR}$} & \multirow{2}{*}{ Tambunan et al., 2019} \\
\hline & INSR-R-5'-TGGCTTTATCTCGGCTCTTG-3' & & \\
\hline \multirow{2}{*}{ CAMKK } & CAMKK-F-5'-GGAGGTGAAGAACTCAGTC-3' & \multirow{2}{*}{ Reverse Transcriptase } & \multirow{2}{*}{ Yu et al., 2004} \\
\hline & CAMKK-R-5'-GGATGCAGCCTCATCTTCCT-3' & & \\
\hline \multirow{2}{*}{ CAMK4 } & CAMK4-F-5'-GCCCTATGCTCTCAAAGTGT-3' & \multirow{2}{*}{ Reverse Transcriptase } & \multirow{2}{*}{ Yu et al., 2004} \\
\hline & CAMK4-R-5'-CACACCGTCTTCATGAGCAC-3' & & \\
\hline \multirow{2}{*}{ IGF1 } & IGF1-F-5'-CTGCCTCTGTGACTTCTTGAAGG-3' & \multirow{2}{*}{ qPCR } & \multirow{2}{*}{ Alzzhanov et al., 2015} \\
\hline & IGF1-R-5'-GTCTTGGGCATGTCAGTGTGG-3' & & \\
\hline \multirow{2}{*}{ GLUT4 } & GLUT4-F-5'-GCCGGGACACTATACCCTA-3' & \multirow{2}{*}{ qPCR } & \multirow{2}{*}{$\begin{array}{l}\text { The GLUT4 primer sequence is our design accor- } \\
\text { ding to ID gene: NC_005109.4 }\end{array}$} \\
\hline & GLUT4-R-5'-TAGTGAGGGTGCCTTGTGC-3' & & \\
\hline \multirow{2}{*}{ GAPDH } & GAPDH-F-5'-ACCACAGTCCATGCCATCAC-3' & \multirow{2}{*}{$\begin{array}{l}\text { Reverse Transcriptase, } \\
\text { qPCR }\end{array}$} & \multirow{2}{*}{ Cho et al., 2008} \\
\hline & GAPDH-R-5'-TCCACCACCCTGTTGCTGTA-3' & & \\
\hline
\end{tabular}

cused on analyzing the role of Caprine CSN1S2 protein in several physiological parameters and the expression of genes and proteins related to diabetes signaling pathway.

\section{MATERIALS AND METHODS}

Preparation and administration of Caprine CSN1S2 protein. Isolation of CSN1S2 bioactive peptide was performed on fresh Ethawah goat milk. The fresh goat milk was obtained from UPT Singosari, East Java, Indonesia. The isolation procedure of CSN1S2 protein was accordant with the previous study (Bia et al., 2015).

Preparation of Experimental Animals. Twenty-four male Wistar rats (Rattus norvegicus), 12 weeks old, with the body weight range of 100-150 grams were obtained from the Laboratory of Experimental Animal, Integrated Research and Testing Laboratory, Gadjah Mada University, Yogyakarta, Indonesia. The animals were acclimatized for 1 week in Animal Laboratory, Biosains Institute, Brawijaya University, Malang, Indonesia. After that, the twenty four rats were randomly divided into eight groups $(n=3)$ : control (untreated) group $(C), C S N 1 S 2$ protein of goat milk group of $375 \mathrm{mg} / \mathrm{kg}$ BW (CM375) group, 750 $\mathrm{mg} / \mathrm{kg}$ BW (CM750) group, $1500 \mathrm{mg} / \mathrm{kg} \mathrm{BW}$ (CM1500) group, diabetes mellitus type 2 (DM) group, diabetes mellitus group treated by CSN1S2 protein of goat milk of $375 \mathrm{mg} / \mathrm{kg} \mathrm{BW}$ (DMM375) group, $750 \mathrm{mg} / \mathrm{kg} \mathrm{BW}$ (DMM750) group, and $1500 \mathrm{mg} / \mathrm{kg}$ BW (DMM1500) group. They were kept in the metabolic cage, exposed to a 12-hour light, and 12-hour dark cycles at RT. The DM rats were established by high cholesterol (45-50\% standard diet, 20-30\% wheat flour, 3-6\% duck egg yolk, $10-20 \%$ goat fat, $2-3 \%$ coconut oil, $0.1-0.5 \%$ cholic acid) feeding for 2 months until they had hypercholesteromia (cholesterol levels $>200 \mathrm{mg} / \mathrm{dl}$ ). A single dosage $(25 \mathrm{mg} / \mathrm{kg} \mathrm{BW})$ of streptozotocin (STZ) was injected intraperitoneally to the hypercholesteromia rats for a week. After the STZ injection, blood glucose and cholesterol levels were monitored every week. DM was diagnosed when blood sugar exceeded $250 \mathrm{mg} / \mathrm{dl}$ (Mostafavinia et al., 2020; Fatchiyah et al., 2019; Moree et al., 2013). The CSN1S2 protein of goat milk treatment was performed for 28 days by oral administration. The physiological parameters (blood glucose and cholesterol level) were evaluated using Nesco MultiCheck (Bioptik Technology, 
Inc., Taiwan). The Institutional Animal Care and Use Committee of the Brawijaya University approved all experimental protocols.

Protein expression analysis. The levels of insulin and $T N F-\alpha$ in rat plasma were measured using ELISA kit (Cat.No E0711Ra (Insulin) and Cat.No E0764Ra (TNF- $\alpha)$, Bioassay Technology Laboratory, China) and SAFAS MP96 microplate reader (Safas, Monaco). The GLUT4, VCAM1 and $\beta$-actin protein expression levels of pancreas tissues were analyzed using Western Blotting. The protein of pancreas tissue was separated in $12.5 \%$ SDS- PAGE and was blotted using the PVDF membrane. The 5\% skim milk in PBS was used to nonspecific protein blocking for an-hour incubation at room temperature. The membrane was incubated overnight at $4^{\circ} \mathrm{C}$ with rabbit anti-GLUT4 (Bioss, USA), rabbit antiVCAM1 (SantaCruz-Biotech., USA), mouse anti $\beta$-actin (SantaCruz-Biotech., USA). The membranes were incubated with polyclonal anti-rabbit $\operatorname{IgG}$ and anti-mouse IgG-AP labeling (KPL, Maryland, USA). The positive reaction was visualized with Western Blue stabilized substrate (KPL, Maryland, USA). The reaction was stopped by distilled water and visualized by ChemiDoc Imaging System (Bio-Rad Laboratories Inc, USA). The intensity of specific protein was measured by Quantity One software.

RNA Isolation and cDNA synthesis. PureZol RNA isolation reagent (Bio-Rad Laboratories, USA) was used to isolate RNA from pancreas of all rat groups. The cDNA synthesis was performed using the iScript cDNA
A)

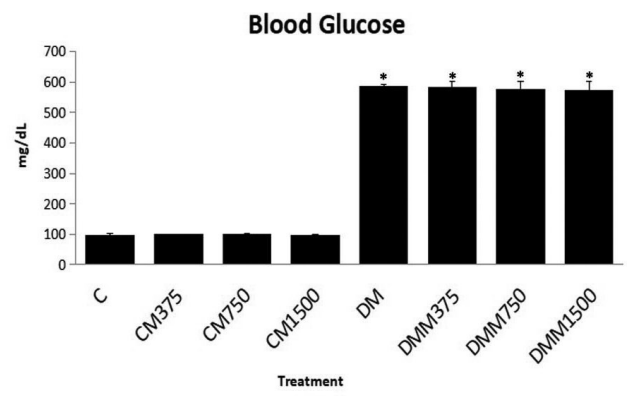

B)

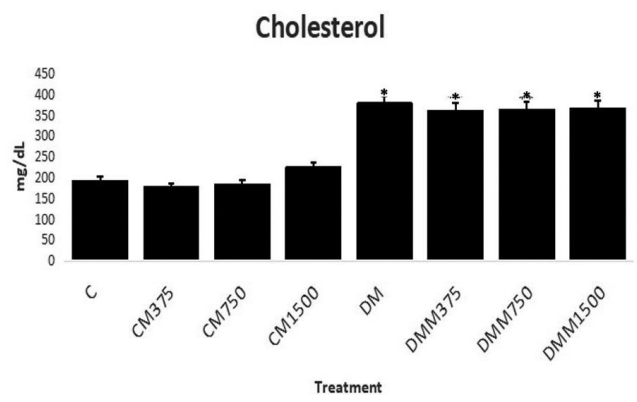

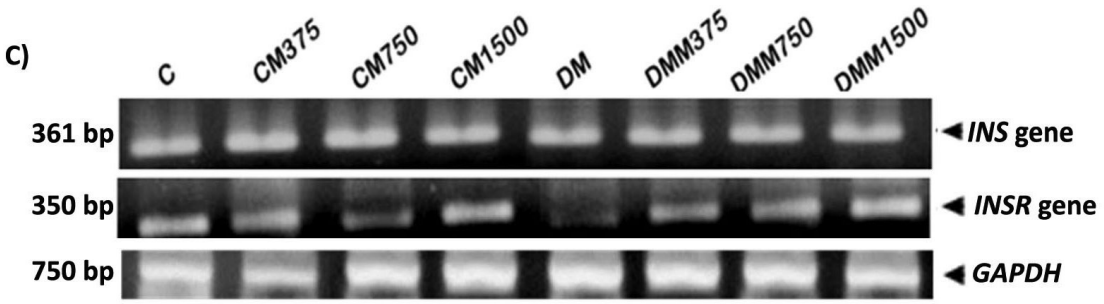

D)

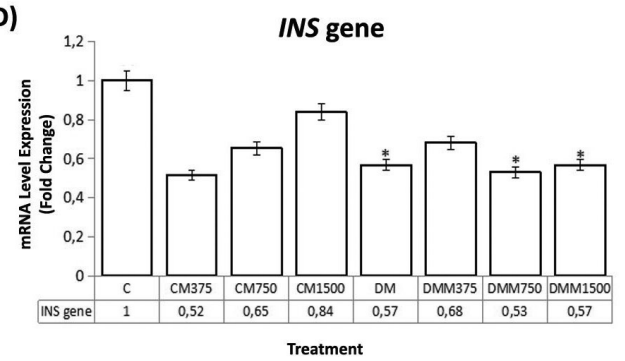

F)

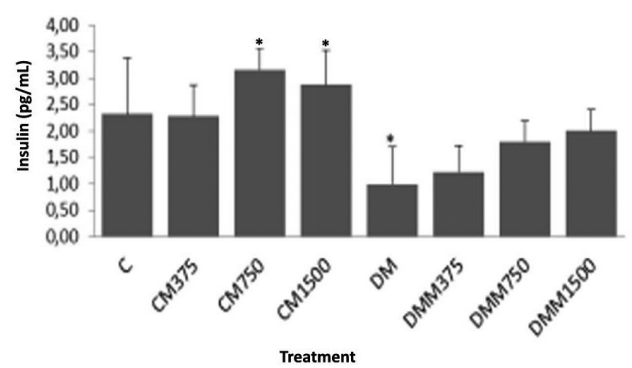

E)

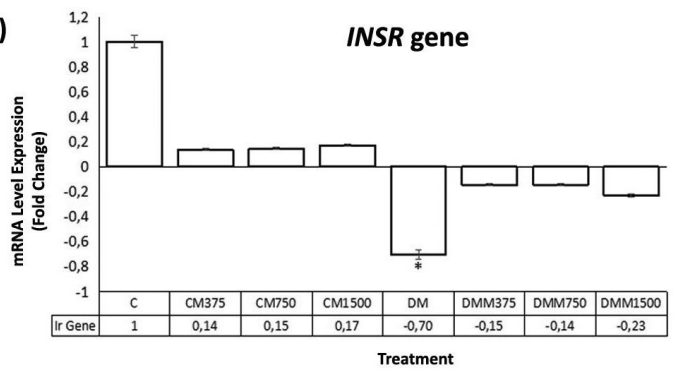

G)

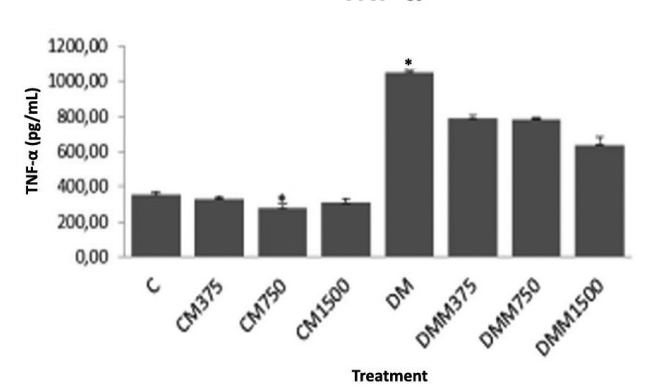

Figure 1. The blood glucose and cholesterol level, mRNA level of INS and INSR genes and insulin and TNF-a protein expression. (A) Blood glucose Level; (B) Cholesterol Level; (C, D and E) mRNA level of insulin (INS), insulin receptor (INSR) and GAPDH genes from rat pancreatic tissues determined by real-time PCR; (F) Level of insulin expression, and (G) Level of TNF-a expression were analyzed by ELISA analysis. All groups were analyzed using ANOVA followed by Duncan test. $\left(^{*}\right)$ indicates a significant difference $(P<0.05)$. 
Synthesis Kit (Bio-Rad Laboratories, USA). The quantity and purity were measured using Nanodrop Spectrophotometer (Implen, Germany).

Determination of mRNA level. The mRNA level of $C A M K 4$ and $C A M K K$ was analyzed by reverse transcription-PCR (C1000 Touch ${ }^{\mathrm{TM}}$ Thermal Cycler, Life Science Research, Bio-Rad) using specific primers (Table 1). The mRNA levels of INS, INSR, GLUT4, and IGF1 genes were amplified with specific primers (Table 1) then measured by Real-Time PCR (CFX-96, Bio-Rad). $G A P D H$ was used as the reference gene in the normalization of the data so its mRNA level was measured using reverse transcription-PCR (RT-PCR) and qPCR. The quantity and purity were tested using Nanodrop Spectrophotometer (Implen, Germany) then the qualities were evaluated by $1.5 \%$ agarose gel electrophoresis (MUPIDex). The band quality was measured using Quantity One software.

Statistical analysis. The data in figures are presented as mean \pm Standard Deviation and differences among groups were analyzed using SPSS 16.0 (SPSS Inc., Chica- go, Illinois, USA). The significant values were measured using One Way ANOVA analysis followed by Duncan test with $P$ value $<0.05$.

\section{RESULTS}

\section{Effect of the CSN1S2 protein on blood glucose and} some diabetes mellitus parameters in gene and protein level

As shown in Fig. 1A and Fig. 1B, the Caprine milk CSN1S2 protein consumption did not cause a significant reduction in blood glucose and cholesterol level in groups of diabetic rats. At the molecular level, genes and protein expression in DM rats significantly improved after Caprine milk CSN1S2 protein administration (Fig. 1C to Fig. 1F). The highest mRNA level of the INS gene was detected in a group of control healthy rats without any treatment $(P<0.05)$, and in the groups of $\mathrm{DM}$ rats no significant change was found (Fig. 1C and Fig. 1D).

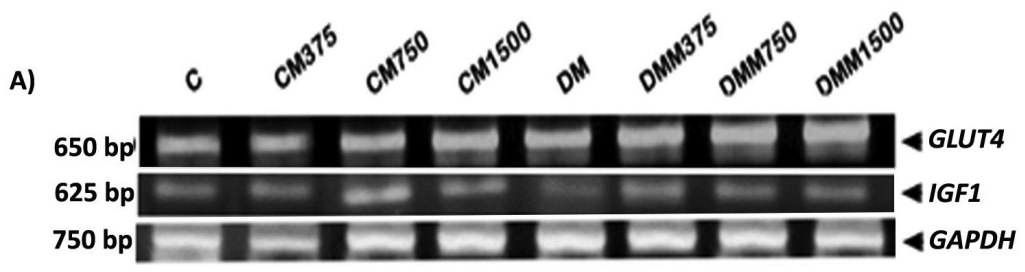

B)

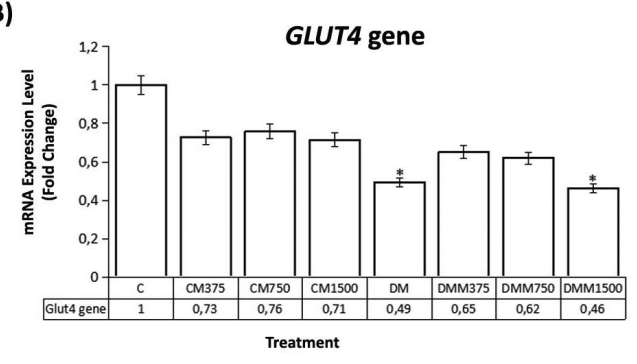

c)

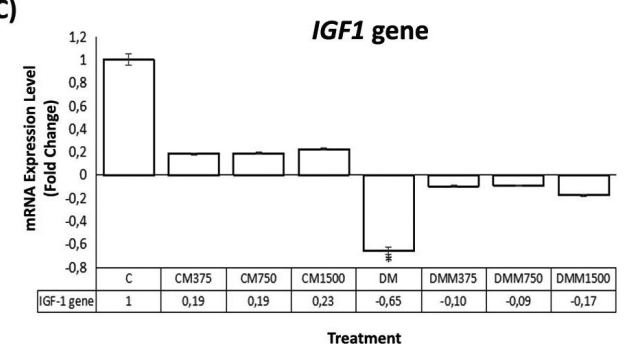

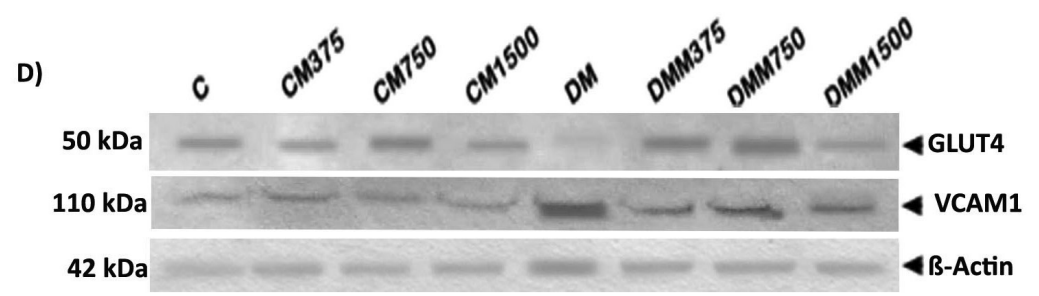

E)

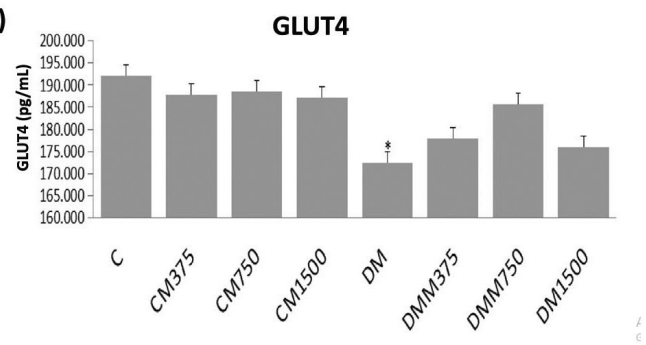

F)

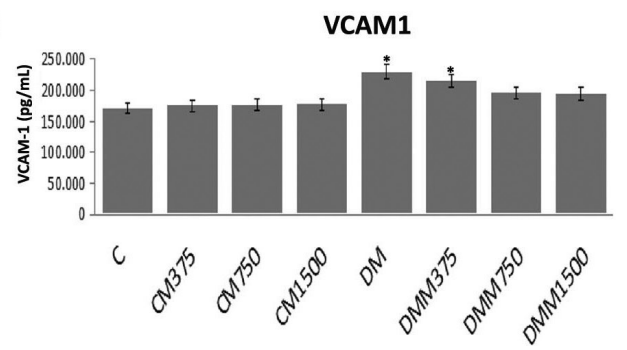

Figure 2. The mRNA level of GLUT4 and IGF1 genes and GLUT4 and VCAM1 protein expression.

$(A, B, C)$ The GLUT4, IGF1 and GAPDH genes expression was determined by real-time PCR. (D, E and F) Western Blotting was used to determine the level of GLUT4, VCAM1 and $\beta$-actin protein expression. All groups were analyzed using ANOVA followed by Duncan test. $(*)$ indicates a significant difference $(P<0.05)$. 
The mRNA expression of the INSR gene in DM rats was significantly $(P<0.05)$ improved in groups treated with all three doses of Caprine milk CSN1S2 protein, but in control healthy rats decreased (Fig. 1E). The insulin level of DM rat pancreatic tissues was the lowest among all groups, and increased after treatment with all three doses (Fig. 1F). On the contrary, tumor necrosis factor- $\alpha$ $(\mathrm{TNF} \alpha)$ expression was the highest in $\mathrm{DM}$ rats $(P<0.05)$ and dropped gradually after all three doses of Caprine milk CSN1S2 protein (Fig. 1G). In general, the treatment with Caprine milk CSN1S2 protein at all tested doses provided the good improvement.

To find out the role of glucose transporter on glucose uptake, this study also analyzed the mRNA levels of the GLUT4 and IGF1 genes using real-time PCR analysis, and the protein expression of GLUT4 and VCAM1 measured by Western blotting using specific monoclonal antibodies. Figure 2 (A, B and C) shows that the highest level of GLUT4 and IGF1 mRNA was detected in the control rats. In DM rats, the mRNA expression of both genes increased after Caprine CSN1S2 protein at doses of 375 and $750 \mathrm{mg} / \mathrm{kg} \mathrm{BW}$. As it is shown in Fig. 2D and Fig. 2E, the level of GLUT4 protein expression in DM rats was most notably enhanced in a group treated with $750 \mathrm{mg} /$ $\mathrm{kg}$ BW of Caprine CSN1S2 protein. The VCAM1 protein expression in DM rats with CSN1S2 treatment was gradually reduced (Fig. 2D and Fig. 2F).

To determine the role of the $\mathrm{Ca}^{2+} /$ calmodulin $(\mathrm{CaM})$ dependent protein kinase $(\mathrm{CaM}-\mathrm{K})$ cascade in enhancing the transcriptional activation of the insulin gene in pancreatic $\beta$-cell, the cDNA of $C A M K K$ and $C A M K 4$ genes was analyzed using real-time PCR. The highest mRNA level of $C A M K 4$ gene was in control rats, but the lowest expression was in DM rats. Interestingly, the highest mRNA level of CAMKK gene (Fig. 3A and Fig. 3B) was in a group of DM rats consuming Caprine CSN1S2 protein at the dose of 750 $\mathrm{mg} / \mathrm{kg} \mathrm{BW}$ (Fig. 3A and Fig. 3C).

\section{DISCUSSION}

Nutrition has the biological function of activating a cascade of genes whose abnormal expression might be related to metabolic diseases. Diabetes is a metabolic disease associated with the mechanism of food intake regulation. Glucose is considered the main nutrient that causes an increase in blood glucose (hyperglycemia). Glucose deficiency leads to hypoglycemia and causes hunger. Rodents, similarly to other mammals, have glucose sensing systems in their brains responsible for regulation of food intake and glucose level homeostasis in target cells or tissues (Dauncey, 2012; Pedersen et al., 2018). In our previous study, we found that the Caprine CSN1S2 protein can safely regulate the biological mechanism in repairing ileum perforation at the doses below $2000 \mathrm{mg} / \mathrm{kg}$ BW and promote optimal functioning of microglial cell proliferation at $750 \mathrm{mg} / \mathrm{kg}$ BW (Agustina et al., 2015; Fatchiyah et al., 2017a; Rika \& Fatchiyah, 2017).

Blood glucose needs to be maintained at a relatively constant level due to its vital role in establishing the physiological mechanisms in mammals. The increased glucose is needed to stimulate the cascade of genes associated with glucose homeostasis mechanisms, such as insulin and insulin receptor genes (Mansour et al., 2017; Kang et al., 2020). In this study, we tried to analyze the role of nutrients from Caprine milk protein in controlling blood glucose and expression of insulin gene as well as other genes related to diabetes. Unfortunately, after giving CSN1S2 protein of Caprine milk in 28 days, the blood glucose of DM rats was not reduced. The CSN1S2 treatment longer than 28 days with an optimal dose is needed to ascertain the change of blood glucose level. However, the biosynthesis of insulin gene improved properly at the molecular levels. These results demonstrate that although the blood glucose as a physiological parameter had not changed, the CSN1S2 protein of Caprine milk could regulate the pancreatic- $\beta$

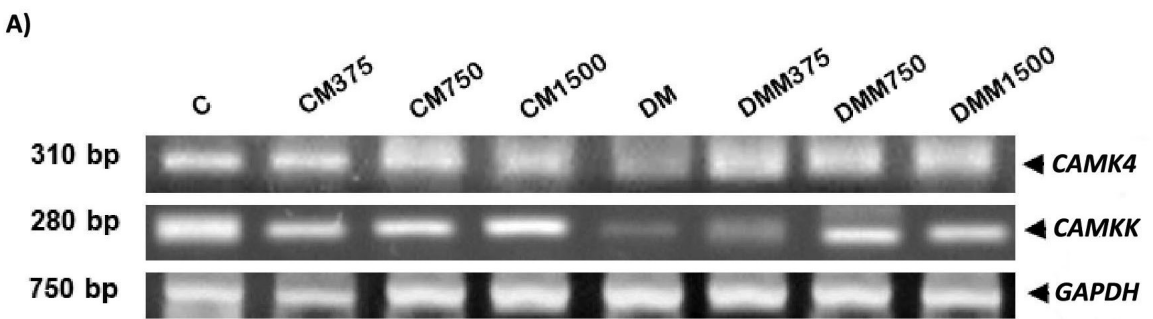

B)

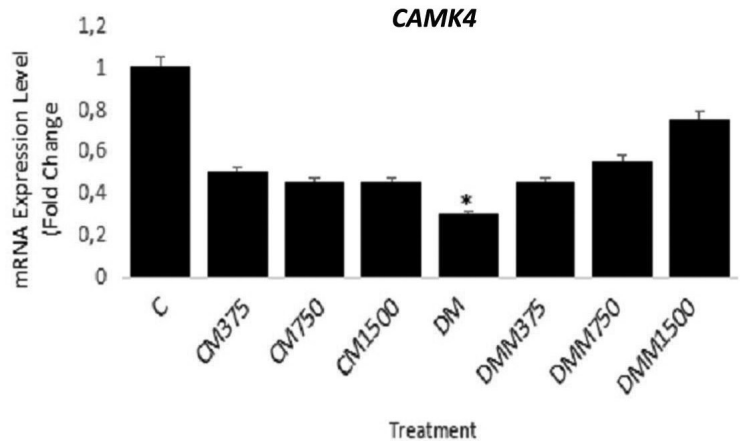

C)

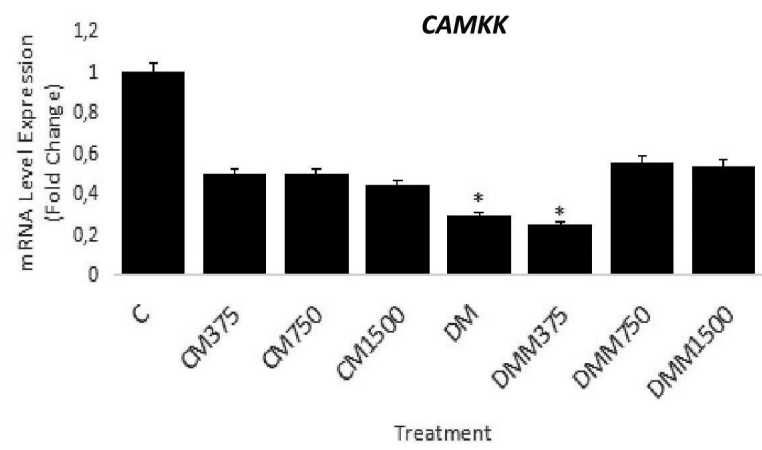

Figure 3. The mRNA Level of CAMK4 and CAMKK genes of rat pancreas tissues were examined by RT-PCR. (A) Electrophoresis in 1.5\% agarose gel, (B) Level of mRNA expression of CAMK4 gene, (C) Level of mRNA expression of CAMKK gene. All groups were analyzed using ANOVA followed by Duncan test . $\left.{ }^{*}\right)$ indicates a significant difference $(P<0.05)$. 
cell insulin and insulin receptor genes expression. This study also showed that the insulin receptor gene expression in control and DM rat groups were more affected by Caprine milk CSN1S2 consumption than the insulin gene itself. It is known that the T2DM patients show an inadequate response to the consumption of a high glycemic load and fail to produce sufficient amount of insulin to mediate glucose uptake (Tucker et al., 2015). In this study, the CSN1S2 of Caprine milk elevated the level of expression of INSR and IGF1 genes, which are important to control glucose uptake, in the DM group. On the contrary, the CSN1S2 protein administration to the healthy rats control group decreased the expression of both genes. Since we did not observe the beneficial effects of CSN1S2 treatment in healthy organisms, we assume that CSN1S2 protein might not be appropriate for the routine daily treatment (28 days in terms of this study) in non-diabetics.

Several genetic and environmental factors determine the insulin signaling related to $\mathrm{TNF}-\alpha$ regulation. The canonical insulin-signaling pathway is triggered by activation of the insulin receptor (IR) tyrosine kinase leading to tyrosine phosphorylation of insulin receptor substrate proteins (IRS1) (Huang \& Czech, 2007). The cytokines tumor necrosis factor alpha $(\mathrm{TNF}-\alpha)$ is an inflammatory mediator against inhibition of insulin signaling. A highfat diet can promote the TNF- $\alpha$ role in stimulating lipolysis in adipocytes and peripheral insulin resistance, which results in hyperglycemia in obese mice (Alipourfard et al., 2019; Gómez-Hernández et al., 2014). The insulin resistance associated with glucose levels in brown fat cells occurs when exposed to the TNF- $\alpha$ directly through the pro-inflammatory pathway, which will interfere with the insulin signaling at the level of IRS1 protein (Lorenzo et al., 2008). This study demonstrated that the insulin expression level increased in DM rats after Caprine milk CSN1S2 protein treatment, contrary to the decreasing level of TNF- $\alpha$ expression in the same groups. It is possible that the CSN1S2 protein stimulates insulin production through the TNF- $\alpha$ signaling pathway at the molecular level. The binding of TNF- $\alpha$ to the cell surface receptor induces the transcription factors activation of nuclear factor- $x \beta(\mathrm{NF}-x \beta)$, which afterward results in the activation of genes involved in the inflammatory process (Alipourfard et al., 2019).

The GLUT4 is an insulin-responsive Glucose transporter type 4, also called Solute carrier family 2 A4 (SLC2A4). GLUT4 glucose transporter has the function as a regulator for whole-body glucose homeostasis and as a mediator for glucose removal from blood circulation. The GLUT4 is found in striated and cardiac muscles, white and brown adipocytes (Huang \& Czech, 2007; Assefa et al., 2017). The IGFBP-2 (Insulin-like growth factor binding protein-2) protein has significant dose-dependent effects on basal glucose uptake as well as the insulin and IGF1 in the 3T3-L1 adipocytes (Assefa et al., 2017). Our research proved that DM rats after consuming CSN1S2 protein of Caprine milk showed the up-regulating of mRNA expression level in the GLUT4 and IGF1 genes at doses of 375 and $750 \mathrm{mg} / \mathrm{kg} \mathrm{BW}$. Moreover, our results proved that the level of GLUT4 protein expression in DM rats improved at $750 \mathrm{mg} / \mathrm{kg}$ BW dose of Caprine CSN1S2 protein treatment. Another study (Augustin, 2010) using knockout mice of SLC2A4'with exon 10 replaced by neomycin cassette exhibited growth-retardation, cardiomegaly, and normoglycemia. Meanwhile, the heterozygote of SLC2A4 $4^{+/-}$mouse has shown diabetes, adult-onset adiposity and insulin resistance in male mice.

Diabetes mellitus is associated with an increased prevalence of endothelial dysfunction and development of atherosclerotic vascular diseases (Altannavch et al., 2004; Cook-Mills et al., 2011). Recent research demonstrated that the expression of human umbilical vein endothelial cells (HUVEC) with high glucose concen-

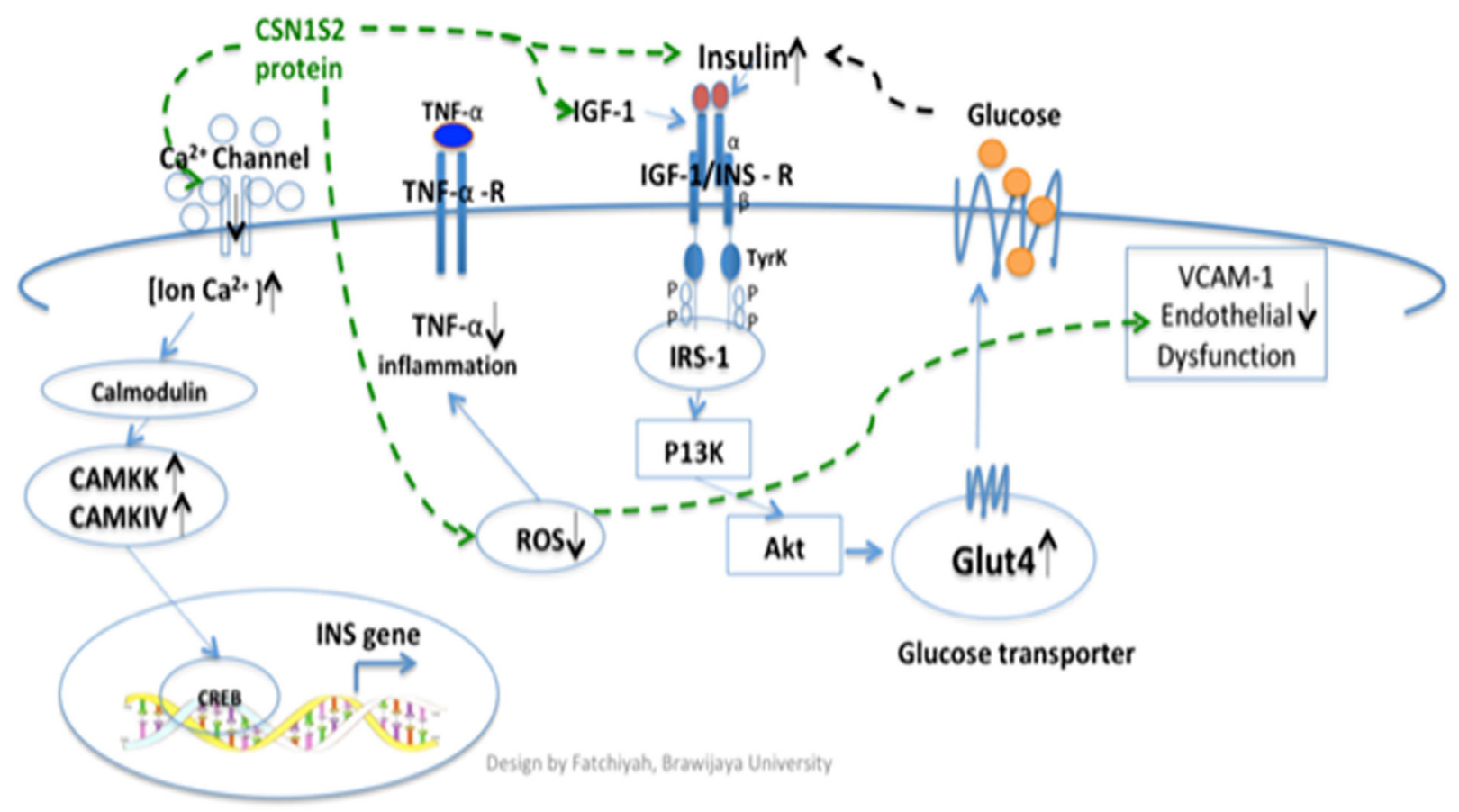

Figure 4. The biological functions of CSN1S2 protein modulate type 2 diabetes cascade signaling at the cellular level.

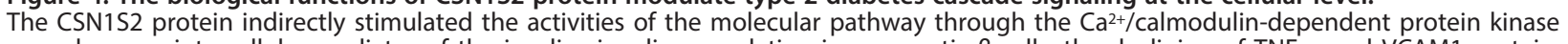
cascade as an intracellular mediator of the insulin signaling regulation in pancreatic $\beta$-cells, the declining of TNF-a and VCAM1 protein, and the improvement of GLUT-4 glucose-transporter in the DM rat target tissues. 
tration induced the expression of intercellular adhesion molecule-1 (ICAM-1), vascular cell adhesion molecule-1 (VCAM1) and endothelial-leukocyte adhesion molecule-1 (ELAM-1) (Altannavch et al., 2004). In the animal mod$\mathrm{el}$, the antioxidant of vascular cell adhesion molecule-1 (VCAM1) protein mediates the adhesion of lymphocytes, eosinophil, basophils and monocytes to vascular endothelium and also provides in leukocyte-endothelial cell signal transduction (Cook-Mills et al., 2011). Our study showed that the VCAM1 protein expression in DM rats was gradually reduced in each dose of CSN1S2 protein of Caprine milk treatment. As dietary goat milk can lower the VCAM1 expression, it indicates the regulation of signal transduction takes place at the cellular level. VCAM1 signaling via ROS and PKC- $\alpha$ activates downstream signals in endothelial cells such as protein tyrosine phosphatase 1B (PTP1B) serine phosphorylation. In the diabetes case, during VCAM1 signaling, PT$\mathrm{P} 1 \mathrm{~B}$ is activated by oxidation. The inhibitors of PTP1B blocked PTP1B de-phosphorylation of the insulin receptor and also prevented the development of diabetes in animal models (Gum et al., 2003; Dubé \& Tremblay, 2005; Cook-Mills et al., 2011).

Our previous study reported that seven of eight peptides residues of the Caprine alpha-S2 casein protein could bind calmodulin on specific sites and might enhance sites for interactions with other cellular molecules (Fatchiyah et al., 2015). The increasing mRNA level of $C A M K K$ and CAMK4 genes in the group of DM rats with Caprine milk of CSN1S2 protein consumption correlated with the increased insulin level at the same dose. This result may indicate that the $\mathrm{Ca}^{2+} /$ calmodulin (CaM)-dependent protein kinase (CaM-Kase) cascade enhances the transcriptional activation of insulin gene in pancreatic $\beta$-cells. A molecule of calmodulin plays a central role as a $\mathrm{Ca}^{2+}$-sensitive target in signal transduction. The activation of $\mathrm{Ca}^{2+}$-binding calmodulin stimulates the conformational calmodulin structure that binds to and activates a large number of target proteins (André et al., 2004; Petegem \& Minor, 2006). The enhancement of intracellular $\mathrm{Ca}^{2+}$ activity and stimulation of $\mathrm{Ca}^{2+} / \mathrm{Calmo-}$ dulin-dependent protein kinase- $\beta$ induced the activation of AMPK on the formation of pathological autophagy in vacuoles of mouse cortical cells (Xie et al., 2013). Another research (Yu et al., 2004) indicated some factors affecting insulin synthesis in pancreatic islet $\beta$-cells and stated that the $\mathrm{Ca}^{2+}$ cascade might play as a key intracellular mediator of glucose-stimulated insulin secretion and gene transcription.

In this study, the Caprine casein-alpha-S2 protein has shown biological functions that can modulate the pathway of insulin signal transduction through the intracellular mediator of the $\mathrm{Ca}^{2+} /$ calmodulin-dependent protein kinase cascade for controlling the homeostasis of insulin metabolism in $\beta$-cells of DM rat pancreatic tissues. And then, the activation of insulin receptor induced the signal transduction of the IRS1 phosphorylation that recruited PI3K and Akt protein and improved the insulin-stimulated translocation of the glucose transporter GLUT-4 at the plasma membrane and resulted in increased glucose uptake. This CSN1S2 protein can also indirectly retrieve the anti-inflammation of tumor necrosis factor- $\alpha$ and reduce the vascular cell adhesion molecule- 1 as one of the biomarkers of endothelial dysfunction for providing the metabolism balancing inside the target tissues in the rat model of type 2 diabetes. This study's conclusions are shown in a schematic figure (Fig. 4). According to our study conclusions, we suggest that the casein-alpha-S2 protein of Caprine milk has valuable therapeutic effects on diabetic treatment in the molecular mechanism of the cellular signaling pathway.

\section{REFERENCES}

Agustina V, Setiawan B, Fatchiyah F (2015) Acute toxicity of caprine alpha S2-casein protein on the microstructures and mineral profiles of rat ileum. Asian Pacific J. Trop. Dis. 5: 721-725. https://doi. org/10.1016/S2222-1808(15)60920-3

Alipourfard I, Datukishvili N, Mikeladze D (2019) TNF- $\alpha$ downregulation modifies insulin receptor substrate 1 (IRS-1) in metabolic signaling of diabetic insulin-resistant hepatocytes. Mediators Inflamm. 2019: https://doi.org/10.1155/2019/3560819

Altannavch T, Roubalová K, Kučera P, Anděl M (2004) Effect of high glucose concentrations on expression of ELAM-1, VCAM-1 and ICAM-1 in HUVEC with and without cytokine activation. Physiol. Res. 53: 77-82.

Alzhanov D, Mukherjee A, Rotwein P (2015) Identifying growth hormone-regulated enhancers in the Igf1 locus. Physiol. Genomics 47: 559-568. https://doi.org/10.1152/physiolgenomics.00062.2015

André I, Kesvatera T, Jönsson B, Ákerfeldt KS, Linse S (2004) The role of electrostatic interactions in calmodulin-peptide complex formation. Biophys. J. 87: 1929-1938. https://doi.org/10.1529/biophysj.104.040998

Assefa B, Mahmoud AM, Pfeiffer AFH, Birkenfeld AL, Spranger J, Arafat AM (2017) Insulin-Like Growth Factor (IGF) binding pro-
tein-2, independently of IGF-1, Induces GLUT-4 translocation and glucose uptake in 3T3-L1 adipocytes. Oxid. Med. Cell. Longev. 2017: https://doi.org/10.1155/2017/3035184

Augustin R (2010) The protein family of glucose transport facilitators: It's not only about glucose after all. IUBMB Life 62: 315-333. https://doi.org/10.1002/iub.315

Bia RR, Virgirinia RP, Setiawan B, Soewondo A, Fatchiyah F (2015) Goat milk CSN1S2 is able to decrease the severity scoring, TNF- $\alpha$, and RAGE expression in complete Freund's adjuvant-induced rheumatoid arthritis model of rats. Biomarkers Genomic Med. 7: 64-71. https://doi.org/10.1016/j.bgm.2015.02.001

Brännmark C, Nyman E, Fagerholm S, Bergenholm L, Ekstrand EM, Cedersund G, Strålfors P (2013) Insulin signaling in type 2 diabetes: Experimental and modeling analyses reveal mechanisms of insulin resistance in human adipocytes. J. Biol. Chem. 288: 9867-9880. https://doi.org/10.1074/jbc.M112.432062

Cepas V, Collino M, Mayo JC, Sainz RM (2020) Redox signaling and advanced glycation endproducts (AGEs) in diet-related diseases. $A n$ tioxidants 9: 1-20. https://doi.org/10.3390/antiox9020142

Cieślak M, Wojtczak A, Cieślak M (2015) Role of pro-inflammatory cytokines of pancreatic islets and prospects of elaboration of new methods for the diabetes treatment. Acta Biochim. Pol. 62: 15-21. https://doi.org/10.18388/abp.2014_853

Cook-Mills JM, Marchese ME, Abdala-Valencia H (2011) Vascular cell adhesion molecule- 1 expression and signaling during disease: Regulation by reactive oxygen species and antioxidants. Antioxidants Redox Signal. 15: 1607-1638. https://doi.org/10.1089/ars.2010.3522

Dauncey MJ (2012) Recent advances in nutrition, genes and brain health. Proc. Nutr. Soc. 71: 581-591. https://doi.org/10.1017/ S0029665112000237

Dubé N, Tremblay ML (2005) Involvement of the small protein tyrosine phosphatases TC-PTP and PTP1B in signal transduction and diseases: From diabetes, obesity to cell cycle, and cancer. Biochim. Biophys. Acta - Proteins Proteomics 1754: 108-117. https://doi. org/10.1016/j.bbapap.2005.07.030

Fatchiyah F, Christian N, Soeatmadji D (2013) Reducing IRS-1 activation cause mutation of tyrosine kinase domain hINSR gene on type-2 diabetes mellitus patients. Bioinformation 9: 853-857. https:// doi.org/10.6026/97320630009853

Fatchiyah, Setiawan B, Kania N, Ohta T, Agustina V, Suharjono (2017a) Safe dosage of caprine CSN1S2 protein from fresh local goat milk for rats evaluated by acute and sub-chronic toxicity testing. J. Math. Fundam. Sci. 49: 90-103. https://doi.org/10.5614/j. math.fund.sci.2017.49.1.8

Fatchiyah F, Hardiyanti F, Widodo N (2015) Selective inhibition on RAGE-binding AGEs required by bioactive peptide alpha-S2 case in protein from goat Ethawah breed milk: Study of biological modeling. Acta Inform. Medica 23: 90-96. https://doi.org/10.5455/ aim.2015.23.90-96

Fatchiyah F, Rahasta AH, Cairns JRK (2017b) Virtual screening and prediction of binding of caprine CSN1S2 protein tryptic peptides to glucokinase. Acta Inform. Medica 25: 225-231. https:// doi. org/10.5455/aim.2017.25.225-231

Fatchiyah F, Nurmasari DA, Masruro N, Rohmah NR, Triprisila LF, Mulyati M, Yamada T, Ohta T (2019) Level of mRNA insulin gene and blood glucose STZ-induced diabetic rat are improved by glucomannan of Amorphophallus muelleri Blume from East Java forest 
Indonesia. J. Tropical Life Sci. 9: 163- 169. https://doi.org/10.11594/ jtls.09.02.05

Fröjdö S, Vidal H, Pirola L (2009) Alterations of insulin signaling in type 2 diabetes: A review of the current evidence from humans. Biochim. Biophys. Acta - Mol. Basis Dis. 1792: 83-92. https://doi. org/10.1016/j.bbadis.2008.10.019

Gómez-Hernández A, Perdomo L, de las Heras N, Beneit N, Escribano O, Otero YF, Guillén C, Díaz-Castroverde S, Gozalbo-López B, Cachofeiro V, Lahera V, Benito M (2014) Antagonistic effect of TNF-alpha and insulin on uncoupling protein 2 (UCP-2) expression and vascular damage. Cardiovasc. Diabetol. 13: 4-13. https://doi. org/10.1186/s12933-014-0108-9

Gum RJ, Gaede LL, Koterski SL, Heindel M, Clampit JE, Zinker BA, Trevillyan JM, Ulrich RG, Jirousek MR, Rondinone CM (2003) Reduction of protein tyrosine phosphatase 1B increases insulindependent signaling in ob/ob mice. Diabetes 52: 21-28. https://doi. org/10.2337/diabetes.52.1.21

Huang S, Czech MP (2007) The GLUT4 Glucose Transporter. Cell Metab. 5: 237-252. https://doi.org/10.1016/j.cmet.2007.03.006

Iovino S, Burkart AM, Kriauciunas K, Warren L, Hughes KJ, Molla M, Lee YK, Patti ME, Kahn CR (2014) Genetic insulin resistance is a potent regulator of gene expression and proliferation in human iPS cells. Diabetes 63: 4130-4142. https://doi.org/10.2337/db14-0109

Kang GG, Francis N, Hill R, Waters D, Blanchard C, Santhakumar AB (2020) Dietary polyphenols and gene expression in molecular pathways associated with type 2 diabetes mellitus: A review. Int. J. Mol. Sci. 21: https://doi.org/10.3390/ijms21010140

Lorenzo M, Fernández-Veledo S, Vila-Bedmar R, Garcia-Guerra L, De Alvaro C, Nieto-Vazquez I (2008) Insulin resistance induced by tumor necrosis factor-alpha in myocytes and brown adipocytes. $J$. Anim. Sci. 86: 94-104. https://doi.org/10.2527/jas.2007-0462

Mansour AA, Nassan MA, Saleh OM, Soliman MM (2017) Protective effect of camel milk as anti-diabetic supplement: biochemical, molecular and immunohistochemical study. African J. Tradit. Complement. Altern. Med. AJTCAM. 14: 108-119. https://doi.org/10.21010/ajtcam.v14i4.13

Moree SS, Kavishankar GB, Rajesha J (2013) Antidiabetic effect of secoisolariciresinol diglucoside in streptozotocin-induced diabetic rats. Phytomedicine 20 237-245. https://doi.org/10.1016/j. phymed.2012.11.011

Mostafavinia A, Amini A, Ghorishi AK, Pouriran R, Bayat M (2016) The effects of dosage and the routes of administrations of streptozotocin and alloxan on induction rate of type1 diabetes mellitus and mortality rate in rats. Lab Anim Res. 32: 160-165. https://doi. org/10.5625/lar.2016.32.3.160

Nobile S, Semple RK, Carnielli VP (2012) A novel mutation of the insulin receptor gene in a preterm infant with Donohue syndrome and heart failure. J. Pediatr. Endocrinol. Metab. 25: 363-366. https:// doi.org/10.1515/jpem-2011-0448

Pedersen C, Porsgaard T, Thomsen M, Rosenkilde MM, Roed NK (2018) Sustained effect of glucagon on body weight and blood glucose: Assessed by continuous glucose monitoring in diabetic rats. PLoS One 13: 1-17. https://doi.org/10.1371/journal.pone.0194468

van Petegem F, Minor DL Jr (2006) The structural biology of voltagegated calcium channel function and regulation. Biochem. Soc. Trans. 34: 887-893. https://doi.org/10.1042/BST0340887

Rika M, Fatchiyah F (2017) Influence of CSN1S2 protein from Caprine milk Etawah Breed (EB) on histology of microglial cells in rat (Rattus norvegicus) type-2 diabetes mellitus (T2DM). AIP Conference Proceedings 1908, 060001. https://doi.org/10.1063/1.5012734

Saif-Ali R, Harun R, Al-Jassabi S, Ngah WZW (2011) Hepatocyte nuclear factor 4 alpha P2 promoter variants associate with insulin resistance. Acta Biochim. Pol. 58: 179-186. https://doi.org/10.18388/ abp.2011_2262

Schwarz NĀ, Blahnik ZJ, Prahadeeswaran S, McKinley-Barnard SK, Holden SL, Waldhelm A (2018) (-)-Epicatechin supplementation inhibits aerobic adaptations to cycling exercise in humans. Front. Nutr. 5: 1-12. https://doi.org/10.3389/fnut.2018.00132

Tambunan SH, Meidinna HN, Rohmah RN, Fatchiyah F (2019) Genomic profile of rIR and rIRR in type 2 diabetes mellitus rat model toward effect of goat milk CSN1S2 protein. J. Phys. Conf. Ser. 1374: 1-6. https://doi.org/10.1088/1742-6596/1374/1/012046

Tucker LA, Erickson A, LeCheminant JD, Bailey BW (2015) Dairy consumption and insulin resistance: the role of body fat, physical activity, and energy intake. J. Diabetes Res. 2015: 1-11. https://doi. org/10.1155/2015/206959

Xie J, Méndez JD, Méndez-Valenzuela V, Aguilar-Hernández MM (2013) Cellular signalling of the receptor for advanced glycation end products (RAGE). Cell. Signal. 25: 2185-2197. https://doi. org/10.1016/j.cellsig.2013.06.013

Yu X, Murao K, Sayo Y, Imachi H, Cao WM, Ohtsuka S, Niimi M, Tokumitsu $\mathrm{H}$, Inuzuka $\mathrm{H}$, Wong $\mathrm{NCW}$, Kobayashi $\mathrm{R}$, Ishida $\mathrm{T}$ (2004) The role of calcium/calmodulin-dependent protein kinase cascade in glucose upregulation of insulin gene expression. Diabetes 53: 1475-1481. https://doi.org/10.2337/diabetes.53.6.1475 